\title{
Prevenção em oncologia: mais rastreios ou melhor intervenção
}

Paulo Santos ${ }^{1,2,3}$

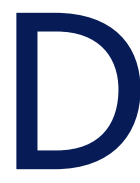

esde a definição de 1986 da Carta de Ottawa, a promoção da saúde é entendida como o processo de capacitação dos indivíduos e das populações para controlarem e melhorarem a sua saúde. ${ }^{1}$ Engloba as três dimensões da proteção da saúde, da prevenção da doença e da educação para a saúde e estende-se longitudinalmente no tempo consoante o nível da história natural da doença que estamos a considerar. ${ }^{2}$

Classicamente, o modelo era estanque nas suas assunções com uma conceptualização rígida entre o que era a prevenção (antes da doença) e o que era o tratamento (depois da doença). No entanto, a introdução na saúde de conhecimento proveniente de áreas como a sociologia, a educação, a economia, a gestão ou a ecologia veio alterar estas fronteiras e permitir uma abordagem mais dinâmica e integradora. ${ }^{3}$ No exemplo da doença cardiovascular, a prevenção do evento coronário é o tratamento dos fatores de risco. Ao assumirmos a elevação dos valores da pressão arterial, por exemplo, como uma doença, com critérios de diagnóstico, tratamento e prognóstico muito bem definidos, estamos a tratar a hipertensão arterial e a prevenir o evento cardiovascular. Se fizermos o mesmo raciocínio para as opções alimentares, nomeadamente quanto à ingestão de sal, em relação à doença hipertensiva, vamos ter uma doença da sobreingestão de sal sódico, com os seus critérios próprios, e tratá-la será prevenir a hipertensão arterial e consequentemente o evento cardiovascular.

Este esquema funcionou bem na doença infeciosa, quase unifatorial na sua génese, e foi particularmente útil na doença cardiovascular. O conhecimento que te-

1. Departamento de Medicina da Comunidade, Informação e Decisão em Saúde (MEDCIDS), Faculdade de Medicina da Universidade do Porto

2. Centro de Investigação em Tecnologias e Serviços de Saúde (CINTESIS), Faculdade de Medicina da Universidade do Porto

3. Editor-adjunto da RPMGF mos da história natural e da fisiopatologia permitiu-nos encontrar pontos de corte onde uma atuação corretamente orientada pode alterar a evolução e efetivamente prevenir a doença, com uma diminuição marcada da morbilidade e mortalidade específicas nos últimos anos em Portugal e no mundo ocidental.

O desafio hoje é a doença oncológica. Dados oficiais do Ministério da Saúde e do Instituto Nacional de Estatística em Portugal mostram que a incidência de cancro na população tem apresentado um crescimento constante de cerca de $3 \%$ ao ano nos últimos anos. A taxa de mortalidade por tumores malignos aumentou de 215,0/100.000 habitantes em 2005 para 257,2/ $/ 100.000$ em 2015. A taxa de anos potenciais de vida perdidos por tumores malignos por 100.000 habitantes aumentou também de 1242,3 para 1258,8 no mesmo período. Temos cada vez mais diagnósticos e cada vez mais doentes a sobreviver ao cancro em Portugal. Mas temos tido alguma dificuldade em encontrar os pontos de corte que permitam uma intervenção eficaz e que mude de facto a história natural da doença.

O caso do cancro do colo uterino é um bom exemplo. Ao conseguirmos identificar lesões pré-malignas e termos a possibilidade de as tratar eficazmente alteramos a história natural da doença, diminuindo a taxa de mortalidade específica de 3,9 para 3,7/100.000 habitantes e a taxa de anos potenciais de vida perdidos de 55,7 para 39,4 entre 2005 e 2015. A vacinação contra o Papilomavírus humano terá também impacto, mas ainda é cedo para o podermos quantificar. Podemos adotar um raciocínio idêntico para o caso do cancro colorectal em relação à deteção e exérese dos pólipos adenomatosos do cólon, e os números irão por certo demonstrá-lo assim que o programa de rastreio atinja uma cobertura significativa na população geral.

Bem diferente é o caso de outros cancros. Na mama, no pulmão, na próstata, na pele, na tiroide, etc..., a pro- 
posta que temos disponível é a deteção precoce, baseada no racional de que quanto mais cedo, na sua história natural, encontrarmos o tumor, maior a probabilidade de termos sucesso na intenção curativa. Mas a diferença é evidente: não estamos a identificar casos de risco aumentado e a diminuir a probabilidade de vir a ter uma doença, mas estamos a identificar casos de cancro instalado e a oferecer um tratamento com uma taxa de eficácia que varia em função de múltiplos fatores. E esta pessoa será um doente com cancro para toda a sua vida.

Interessa definir de forma clara e sem preconceitos se a intervenção nesta fase altera de facto a história natural da doença, como parece ser o caso do rastreio do cancro da mama nas mulheres até aos 74 anos mas não nas que têm idade superior, ${ }^{4,5}$ mas não parece ser o caso no rastreio do cancro da próstata. ${ }^{6}$ Por isto, os programas de rastreio de base populacional propostos pelo Programa Nacional para as Doenças Oncológicas da Direção Geral da Saúde e recentemente atualizados pelo Despacho n. ${ }^{\circ}$ 8254/2017, de 21/09/2017, do Secretário de Estado Adjunto e da Saúde, focam alguns cancros e não outros. Não invalida que a cada doente seja oferecido o melhor nível de cuidados ao alcance do médico, com correção e delicadeza, para promover ou restituir a saúde, conservar a vida e a sua qualidade, suavizar o sofrimento, no pleno respeito pela dignidade do ser humano, conforme o nosso compromisso deontológico e ético enquanto médicos.

Tem de se referir que a modelação estatística utilizada para suportar as conclusões está dependente de variáveis que mudam ao longo do tempo como a esperança média de vida da população, a probabilidade individual de doença, e os testes diagnósticos e os tratamentos disponíveis, o que obriga a ajustar constantemente as recomendações à evidência existente, pesando o benefício e os custos diretos e indiretos da intervenção.

Na falta de uma intervenção externa verdadeiramente disruptiva, voltamo-nos para a pessoa humana, a principal responsável pela sua própria saúde, na sua integridade biológica, psicológica, social e espiritual. A causa do cancro está na interação entre os fatores genéticos e três categorias de agentes externos: agentes físicos, agentes químicos e agentes biológicos, muitas vezes modeláveis pelas opções de cada um..$^{7}$ O consumo de tabaco, o consumo de bebidas contendo álcool, os erros nas opções alimentares e a inatividade física são determinantes major que, se melhorados, podem diminuir significativamente a incidência de novos casos de cancro, ${ }^{7}$ e de muitas outras doenças não transmissíveis. E estes fatores dependem de cada um nas decisões do dia-a-dia, transferindo o foco da atenção em saúde do combate à doença para a promoção de uma vida saudável. É necessário, sobretudo ao nível dos Cuidados de Saúde Primários, assumir a opção por uma melhor literacia em saúde, capacitando a pessoa para obter, processar e entender a informação básica em saúde, bem como o conhecimento dos serviços necessários para fazer opções mais apropriadas, ${ }^{8}$ não porque a isso é obrigada por uma regulamentação imposta superiormente, ${ }^{9}$ mas porque percebe que é esse o verdadeiro fator chave para uma melhor prevenção ${ }^{10}$ que possibilite mais e melhor saúde.

\section{REFERÊNCIAS BIBLIOGRÁFICAS}

1. Ottawa charter for health promotion. Can J Public Health. 1986;77(6): 425-30.

2. Tannahill A. What is health promotion? Health Education Journal. 1985;44(4):167-8.

3. Tannahill A. Health promotion: the Tannahill model revisited. Public Health. 2009;123(5):396-9.

4. Nelson HD, Fu R, Cantor A, Pappas M, Daeges M, Humphrey L. Effectiveness of Breast Cancer Screening: Systematic Review and Metaanalysis to Update the 2009 U.S. Preventive Services Task Force Recommendation. Ann Intern Med. 2016;164(4):244-55.

5. Nelson HD, Pappas M, Cantor A, Griffin J, Daeges M, Humphrey L. Harms of Breast Cancer Screening: Systematic Review to Update the 2009 U.S. Preventive Services Task Force Recommendation. Ann Intern Med. 2016;164(4):256-67.

6. Ilic D, Neuberger MM, Djulbegovic M, Dahm P. Screening for prostate cancer. Cochrane Database Syst Rev. 2013(1):CD004720.

7. Stewart BW, Wild C, International Agency for Research on Cancer, World Health Organization. World cancer report 2014. Lyon, France Geneva, Switzerland: International Agency for Research on CancerWHO Press; 2014. xiv, 630 pages $p$.

8. Ratzan S, Parker R. Introduction. In: Selden CR, Zorn M, Ratzan S, Parker RM, editors. Health literacy Current bibliographies in medicine 20001. Bethesda, Md. (8600 Rockville Pike, Bethesda 20894): U.S. Dept. of Health and Human Services, Public Health Service, National Institutes of Health, National Library of Medicine, Reference Section,; 2000. p. v-vii.

9. Santos P, Nazaré I, Martins C, Sá L, Couto L, Hespanhol A. The Portuguese Guidelines and Patients Values. Acta Med Port. 2015;28(6):754-9.

10. Santos P, Sá L, Couto L, Hespanhol A. Health literacy as a key for effective preventive medicine. Cogent Social Sciences. 2017;3(1): 1407522.

\section{ENDEREÇO PARA CORRESPONDÊNCIA}

E-mail: psantosdr@med.up.pt. 